\title{
Heterogeneous Partnerships in A Fragile Environment: A Study of Motives for Collaboration in Myanmar
}

\author{
${ }^{1}$ Public Administration, Hochschule fur Wirtschaft und Recht Berlin, Berlin, Germany, E-mail: isabella.nolte@gmail.com. \\ https://orcid.org/0000-0002-9585-7749.
}

\begin{abstract}
:
Relationships between international aid organizations and their local partners in the Global South are often problematic, with criticisms relating to paternalistic structures and inequality. In this study, empirical data from organizations working in heterogeneous partnerships in Myanmar is used to analyse motives for collaboration between international and local organizations. This study's findings stress that both local and international organizations often focus on short-term program needs, while motives that relate to organizational goals, such as networking, improved reputation, or advocacy, are less prevailing. For development assistance to be successful in the long run, power imbalances between international and local organizations need to be addressed and a stronger sense of equality between partnering organizations must be promoted.
\end{abstract}

Keywords: partnership, collaboration, INGOs, development, Myanmar

DOI: $10.1515 / \mathrm{npf}-2019-0008$

\section{Introduction}

Large numbers of international public and nonprofit organizations are engaged in countries receiving development assistance to aid with acute and chronic problems, such as disasters, poverty, and political instability (Nolte, Martin, and Boenigk 2012). Foreign aid that is provided by the international donor community, for example in form of Official Development Assistance (ODA), has risen over the last couple of years and decades (OECD 2017, 2019; United Nations 2015), and is increasingly allocated through the nonprofit sector (Burger, Owens, and Prakash 2018). International donors and funding agencies stress that development assistance should be provided in partnership with local organizations.

This study explores the partnering of international aid organizations with local organizations, so-called 'heterogeneous partnerships'. Collaboration and partnership between international and local organizations have been put on the political agenda and are addressed in several strategies, such as the Millennium Development Goals, followed by the Sustainable Development Goals (United Nations 2015, 2017) and the Grand Bargain (International Council of Voluntary Agencies 2017). Such interorganizational partnerships describe the working together of different actors towards mutually agreed objectives (Brinkerhoff 2002).

Researchers and practitioners alike criticize relationships of dependency and inequality prevailing in heterogeneous partnerships (Ahmad 2006; Curtis 2004; Inter-Agency Standing Committee 2010; Pishchikova 2014), stressing the need for a closer analysis of this type of collaboration. Holcombe et al. discuss the term 'partnership' in the development context and criticize its use as "a feel-good label that may mask power inequalities" $(2004,195)$. Up to this point, it remains to be discussed whether the international community helps countries in the Global South becoming more resilient and self-sustainable, or if it rather creates a situation of dependency on foreign aid - often described as 'charity hazard' (Raschky and Weck-Hannemann 2007) - that discredits the whole concept of partnership (Pishchikova 2014).

To learn about the relationship between international and local partners, I use the case of heterogeneous partnerships in Myanmar, a country that has experienced dramatic political change over the last couple of decades that strongly affected the relationship between local government, local NGOs, and their international counterparts (Matelski 2016). This case is typical of the kind of heterogeneous partnerships involving international and local aid organizations in a fragile environment. Addressing the criticism of a lack of equality and consequently a lack of effectiveness, this study contributes to our understanding of perceptions of these different actors and different types of motives for collaboration prevailing within heterogeneous partnerships. This

Isabella M. Nolte is the corresponding author.

(c) BY 2019 Nolte, published by De Gruyter.

This work is licensed under the Creative Commons Attribution 4.o Public License. 
research addresses two main questions: (1) What do we know about heterogeneous partnerships for development? And (2) what types of motives for collaboration do global and local organizations pursue?

The following section reviews the existing literature on interorganizational collaboration, with a focus on motives for collaboration. This study follows an exploratory approach, collecting empirical evidence from interviews and open-ended survey responses from members of heterogeneous partnerships in Myanmar. The article closes with a discussion of the findings and resulting implications for research and practice.

\section{Literature Review and Research Framework}

Scholars from the field of public, nonprofit, and development studies have done a lot of research on interorganizational partnerships for social service provision (e. g. Brinkerhoff 2002; Gazley and Brudney 2007; Lister 2001; Salamon 1995). Salamon (1995) explains interorganizational partnerships involving nonprofit organizations with theories of voluntary failure and third-party government. While nonprofit organizations struggle for (mostly financial) resources and may at times fail to provide services for minorities that exist outside their defined 'target groups', constituting voluntary failure, governmental organizations resort to nonprofit organizations to fulfil tasks of public interest, the so-called third-party government. A frequent risk associated with this complementary relationship between government and nonprofit is that governmental agencies see their nonprofit partners as agents, rather than equal partners, disrupting the government-nonprofit relationship (Kendall and Knapp 1997; Young 2000).

While mutuality is stressed as a main characteristic of well-performing partnerships (Brinkerhoff 2002), experiences from the field show that inequalities between different organizational partners often exist (Lister 2001; Waugh 2000). Gazley and Brudney note that a lot of the scholarship on interorganizational collaboration is normative, presenting collaboration as a goal in itself, neglecting institutional risks, such as mission drift, the loss of institutional autonomy and the expenditure of institutional time and resources, that are frequently associated with the formation of interorganizational partnerships (Gazley and Brudney 2007; Kendall and Knapp 1997). While existing research focuses on an analysis of interorganizational collaborations from a single region or country, more insights are needed into interorganizational collaboration across borders (Pishchikova 2014).

\subsection{Heterogeneous Partnerships}

In this study, the term heterogeneous partnership is used to characterize collaborations that are formed between organizations from the inter- or supranational arena and local organizations in regions receiving development assistance (Burgess 2014). Inter- and supranational organizations include public and nonprofit organizations such as United Nations agencies, public agencies like the UK-based Department for International Development and traditional international non-governmental organizations (INGOs) like Trócaire or Médecins Sans Frontières. Local actors include local public and nonprofit organizations with regional or national scope. This involves local non-governmental organizations, such as faith-based organizations and charities, as well as governmental agencies on the regional and national level.

Collaboration with local partners is politically promoted, for example by the Grand Bargain, a commitment to improve the provision of humanitarian aid made by a number of the main players in international development. As part of this agreement, organizations such as the European Commission, UNICEF, and Australian Aid committed themselves to engage in partnership with local and national organizations and to develop standards for community engagement and participation (International Council of Voluntary Agencies 2017).

To the researcher analysing partnerships within a single region and sector, heterogeneous partnerships may sound like a paradox, resembling situations that may be solved in a contractual setting, rather than using the label 'partnership' that is usually associated with flat hierarchies (Vangen, Hayes, and Cornforth 2015). Curtis (2004) expresses criticism towards the label of partnership, indicating that in aid administration, donor and recipient organizations follow different motives and experience power inequalities. However, in the field of social services and development assistance, this label is frequently used, despite the seemingly different composition and power relationship between partnering organizations (see, for example United Nations 2015, 2017).

Problems that arise within heterogeneous partnerships are often described through the lens of principalagent theory (Ashman 2001; Chikoto 2015). International organizations usually act as funding agencies, or principals, while local partners act as agents, fulfilling tasks and providing services on the ground. The normative assumption is that the principal who provides resources should be the one to set the rules and to decide on how the resources shall be used (Ashman 2001). However, such unilateral control is against the common notion of partnership, and Ashman (2001) states that: "[a]lthough agency theory is widely applied to relationships 
framed as interorganizational cooperation, its normative assumptions make it valid only for problems of compliance, not collaboration" (87-88).

\subsection{Motives for Collaboration}

In the existing literature, resource dependencies and funding requirements are frequently mentioned as triggers for partnership between international and local organizations (Ahmed et al. 2016; Hjortsø and Meilby 2013). However, the current literature fails to elaborate on the types of motives that shape the relationship between these different actors. In the following paragraphs, distinct motives that are pursued by organizations engaged in development assistance are explored.

Two types of motives that exist within organizations providing public services and that can be adjusted to the context of aid provision are (1) program needs and (2) organizational goals (Chen and Graddy 2010). Program needs derive from the need to acquire resources to achieve desired program outcomes, as described in resource dependence theory (Pfeffer and Salancik 1978). Single organizations experience different resource constraints, e. g. in the field of technical expertise or financial resources. Power imbalances are frequently associated with resource dependence theory, when organizations are in need of resources that are controlled by other organizations. These resource needs then have to be balanced with a desire for institutional autonomy and power (Gulati and Sytch 2007; O'Brien and Evans 2017).

Pfeffer and Salancik (1978) also elaborate on resource interdependence, when organizations partner to exchange resources. While power imbalance is an expression of differences in power between organizations, mutual dependence relates to resource interdependence and the degree to which each organization is dependent on the partnering organization's resources (Casciaro and Piskorski 2005). The existing literature primarily assesses relationships of power imbalance, as described by resource dependency theory, while less research focuses on the study of mutual dependence created through resource interdependency (Gulati and Sytch 2007).

Resource dependencies leading to power imbalances are prominent features in the area of development assistance (Chahim and Prakash 2014; Hudock 1995; Khieng and Dahles 2015). However, not only resource dependence, but resource interdependence often exists: Organizations are dependent on each others' resources, for example those organizations that provide funding and technical expertise for one organization may need local knowledge and cultural skills from that same organization to run their programs. Resource interdependence can facilitate collaboration and partnership (Pishchikova 2014; Saidel 1991) and distinct motives for collaboration leading to resource interdependence need to be explored.

While resources like funding and knowledge that are needed by local organizations are more frequently mentioned in the existing literature (e. g. Burger and Owens 2013; Khieng and Dahles 2015; Koehn 2012), program needs from the international organizations' point of view are often not considered (Ahmed et al. 2016; Hjortsø and Meilby 2013). Holcombe et al. (2004) found that tapping into local knowledge can help international organizations achieve their project goals, while Raufflet, Berranger, and Guin (2008) regarded financial returns as one motive for international organizations to engage in collaboration. However, more insights into the reasons for international organizations to partner with local organizations are needed. International organizations concentrate on their managerial development tasks and often do not seem to need resources provided by local partners (Elbers, Knippenberg, and Schulpen 2014). Yet, an absence of program needs from the global partners' side can disrupt resource interdependence, causing power imbalances and negatively affecting the partnership and its performance (Curtis 2004; Spence and Ninnes 2007). Different program needs that can be pursued by members of local and international organizations are listed in Figure 1.

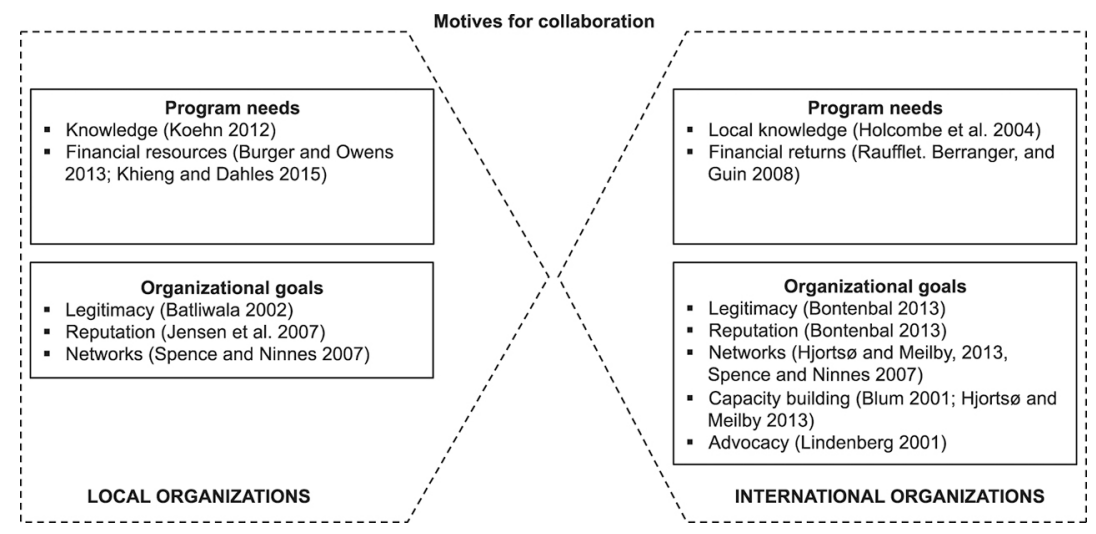

Figure 1: A framework for motives for collaboration within heterogeneous partnerships. 
The second type of motives for collaboration, organizational goals, relate to the overall strategic purpose of an organization, considering needs that go beyond the single project or program. Thus, organizational goals refer to things such as the seeking of legitimacy, improvements of organizational reputation, or a widening of existing networks with partner organizations and beneficiaries (Bontenbal 2013; Chen and Graddy 2010; Hjortsø and Meilby 2013; Jensen et al. 2007; Spence and Ninnes 2007).

Legitimacy theory supports the existence of organizational goals when organizations are entering a partnership (Suchman 1995). With legitimacy, researchers refer to external and internal stakeholder's perception of an organization's actions as desirable and appropriate (Provan, Kenis, and Human 2008). Three indicators can be used to assess legitimacy in collaborations. One is the motivation to meet funding agency expectations. A second indicator can be derived from institutional theory, which suggests that organizations enter collaborations to improve one's organizational reputation. Organizations aim to collaborate with well-respected partners or engage in partnership with organizations with a positive social image to put their own organization in a good light (Batliwala 2002; Bontenbal 2013). This is also relevant for the third indicator, where organizations engage in collaboration to widen their networks and establish future relationships (Chen and Graddy 2010; Hjortsø and Meilby 2013). Networking and strengthened relationships can facilitate learning and enhance organizational prospects for sustainability (Spence and Ninnes 2007). In a study about collaborations between municipalities in the Global North (Netherlands) with municipalities in the Global South (Peru, Nicaragua, and South Africa), Bontenbal (2013) found that international organizations aim to improve job satisfaction, publicity, and their social image when collaborating with partners in the south. Thus, organizations tend to behave in a socially desirable way and aim to increase their legitimacy in front of their stakeholders.

Further organizational goals that are frequently attributed to international organizations relate to capacity building and advocacy. International organizations collaborate with local partners to build local capacity, allowing them to ultimately withdraw from a project or program in the Global South (Blum 2001). International organizations also take on advocacy roles, being able to coordinate global advocacy agendas and challenging local government practices that may hinder aid activities on the ground (Lindenberg 2001). As existing studies primarily highlight a lack of local involvement, those motives that relate to local capacity building seem to be less prevalent than those that relate to legitimacy and reputation. The different types of organizational goals applying to local and international organizations are shown in Figure 1.

\section{Heterogeneous Partnerships in a Changing Environment: The Case of Myanmar}

This study is set in the context of Myanmar and makes a contribution to our understanding of collaborations involving international and local aid organizations in fragile states. Following years of economic isolation, Myanhas experienced a substantial political liberalization and reforms after elections in 2010, bringing about an increased interest of the international donor community (Matelski 2016). Since 2008, Myanmar has seen a large inflow of international public and nonprofit organizations and funds, initiated by the response to the damage caused by cyclone Nargis (Asian Development Bank 2015). Net ODA has increased from USD 1,384.5 million in 2014 to USD 1,542.8 million in 2017, with most of the aid going into sectors relating to the development of economic and social infrastructure and services (OECD 2019).

The civil society sector in Myanmar originally consisted of Buddhist and other faith-based groups that mainly engaged in activities relating to poverty reduction, education, and community development. Due to interventions of the military government who aimed to reduce the influence of Buddhist monks, Buddhist organizations traditionally operate on the local level, while other faith-based organizations, for example Christian or Islamic organizations, have a longer history in collaborating with international partners (Cheesman 2010; Matelski 2016). Local NGOs engaging in development and humanitarian aid mainly emerged since 2008, following the disaster response to cyclone Nargis (Asian Development Bank 2015). Armed conflicts and refugees from many of the country's different ethnic groups subsequently triggered further NGO activity in areas the public sector would or could not engage in (Transnational Institute and Burma Center Netherlands 2011). However, many civil society organizations in Myanmar are not formally registered with the government out of a fear of repression and a desire for independence, making them more dependent on foreign support (Matelski 2016). Collaboration between international public and nonprofit organizations and local nonprofits can be seen in many programs and projects, and the local nonprofit sector is now growing and becoming more experienced in new areas, such as education, health care, and agriculture (Asian Development Bank 2015).

While the local public sector was moving towards democratization and a larger involvement in the provision of aid from 2011, it has experienced drawbacks since 2016 with the escalating conflict over the Rohingya minorities resulting in hundreds of thousands of refugees from the country fleeing violence and persecution, and the subsequent attempts at intervention from authorities abroad (Wake and Yu 2018). The results of this recent 
crisis are likely to stir further needs for development assistance and humanitarian relief, calling for a continued involvement of inter- and supranational actors in the country. While only nine per cent of ODA in 2015-2016 were used for humanitarian aid, this sector is likely to gain importance in the future, already increasing to ten per cent in 2016-2017 (OECD 2019).

Despite the enormous needs for an efficient management of development assistance and humanitarian relief in Myanmar, research on the management of development and humanitarian services in Asia centres on neighbouring countries, such as Bangladesh or Thailand, and on transitioning countries, such as India or China. Research on the Myanmar case can help to learn about heterogeneous partnerships in a fragile environment.

\subsection{Data Collection}

An initial field visit to Myanmar was conducted in November 2016. Semi-structured interviews with seven members of INGOs active in the country were held to discuss the relationship between international and local organizations and to learn about prevailing motives for collaboration. In addition to the interviews, a coordination meeting of INGOs was attended and materials relating to collaboration and performance evaluation in development projects carried out in the country were reviewed. Interviews with experts and the document review supported issues that were raised in the literature, talking about different perceptions and motivations of partners in the field. Topics that were addressed included competing motives between international and local organization, as well as a perceived lack of local knowledge on the international side. Based on the results of the initial visit, an online survey was developed and administered in 2017. Using contact information from a database of the Myanmar Information Management Unit, 772 members of different international and local organizations engaged in aid operations in Myanmar were invited to participate in the survey. The survey was provided in English and Burmese. 268 responses were received, yielding a response rate of $35 \%$.

Questions addressing motives for collaboration and community involvement were partly open-ended. These responses were content-analysed using NVivo, a software package for qualitative data analysis that facilitates the systematic analysis and coding of qualitative data. 188 responses were included in the qualitative analysis, excluding those cases that did not answer the relevant open-ended questions for this part. Deductive coding was applied, designing preliminary codes in line with the dimensions derived from the literature in a first step. The following open-ended questions relating to the topic of motives for collaboration were asked in the survey and made up two overall themes:

1. Can you please explain why you partner with local organization(s) on the regional and national level?

2. Can you please explain why you partner with international organization(s)?

In a second step, the coding scheme was refined and sub-codes for each category were formed based on the review of the existing literature and complemented during the analysis, reviewing the text multiple times.

\subsection{Sample Characteristics}

Sample characteristics are show in Table 1. Of the 268 surveyed respondents, $53 \%$ reported they worked for an international organization, headquartered in a country other than Myanmar, while $45 \%$ stated they worked for a regional or national organization based in Myanmar. The vast majority, almost $80 \%$ of the respondents, stated that they worked for a nonprofit organization, nine percent worked for a public organization, a further nine percent mentioned they worked for another sector organization, mostly mentioning social enterprises and research institutions.

Table 1: Sample characteristics.

\begin{tabular}{lll}
\hline Type of organization & Valid percentage & Number of responses \\
\hline International organization & 53 & 141 \\
Regional organization & 11 & 29 \\
National organization & 34 & 90 \\
Other & 3 & 8 \\
& & 211 \\
Nonprofit organization & 79 & 23 \\
Public organization & 9 & 9 \\
Private organization & 3 &
\end{tabular}




\begin{tabular}{lll}
\hline Position & & \\
Director, Country Director & 39 & 104 \\
Project/Program Manager & 20 & 53 \\
Coordinator, Project Coordinator & 16 & 41 \\
Program Director & 5 & 14 \\
Secretary, Assistant & 4 & 10 \\
Other, e. g. advisor, specialist & 16 & 42
\end{tabular}

\begin{tabular}{ll}
\hline Main areas of activity & Number \\
Health, WaSH & 51 \\
Livelihoods and nutrition & 43 \\
Education & 29 \\
Peace and conflict resolution & 21 \\
Economics and governance & 19 \\
DRR, disaster response & 18 \\
Business and finance & 11 \\
Gender and equality & 9 \\
Children and youth & 5 \\
Other, e. g. capacity building, development & 47 \\
\hline
\end{tabular}

The majority of the respondents were directly involved in project and program management, e. g. as country directors, project and/or program managers, and project coordinators. Total numbers and valid percentages (excluding missing values) are presented in Table 1. Each respondent could name up to three main areas their organization was engaged in. Organizations were active in diverse activities such as health, water, sanitation and hygiene (WaSH), livelihoods and nutrition, economics and governance, peace and conflict resolution, disaster risk reduction (DRR) and disaster response. Project areas are listed in Table 1, 'other' project areas were assigned if a project did not clearly fall into one area or if very general descriptions such as 'capacity building' or 'development' were used.

\section{Perceptions of Global and Local Partners in Myanmar}

The following paragraphs distinguish between motives to collaborate with international organizations from the local organizations' point of view and motives to collaborate with local organizations from the international organizations' perspective. These results are summarized in Table 2. Of the analysed 188 responses, 111 respondents worked for an international organization, the remaining 77 respondents worked for a local organization.

Table 2: Motives for collaboration.

\begin{tabular}{llll}
\hline Code & Sub-code & $\begin{array}{l}\text { Number of coding } \\
\text { references }\end{array}$ & Percentage \\
\hline Motives to collaborate with local organizations $(\mathbf{n}=\mathbf{1 1 1})$ & & 29 \\
Program needs & Local knowledge & 32 & 17 \\
& Access to beneficiaries & 19 & 8 \\
& Geographic access & 9 & 6 \\
& Local resources, local skills & 7 & 5 \\
& Use cultural competence & 6 & \\
& Sustainability & 20 & 18 \\
Organizational goals & Local capacity building & 20 & 18 \\
& Legal requirements & 5 & 5 \\
& Lower cost & 3 & 3 \\
& Improved reputation & 2 & 2 \\
& & \\
\end{tabular}

Motives to collaborate with international organizations $(n=77)$

Program needs $\quad$ Funding, financial 36 


\begin{tabular}{llll} 
Organizational goals & Networking, global & 9 & 12 \\
& & 8 & 10 \\
Outreach & Capacity building & 4 & 5 \\
Advocacy & Advacy \\
\hline
\end{tabular}

\subsection{Motives to Collaborate with Local Organizations}

The biggest reason for members of international organizations to collaborate with local actors was to profit from local knowledge in one way or another (mentioned by $29 \%$ of the respondents). As one respondent noted: "Local organizations are important partners as they know the local context and understand what the local people need." And "[l]ocal organizations are the ones who can get quick access to the areas, know the resources, capacity and risks of the affected area [more] than the outsiders, and they are the first responders." "[T]hey understand the culture, geographical conditions and village situations more than we do."

Another major reason to collaborate with local organizations was to get access to beneficiaries (mentioned by $17 \%$ ). As one respondent stated: “Local organizations [...] represent a key interlocutor between communities and more formal peace process stakeholders and government representatives." And "[l]ocal organizations have local knowledge, networks, and access to poor and vulnerable people who are hard to reach."

Some respondents mentioned they engaged with local partner organizations to gain geographic access, something that seemed of particular importance in a fragile state like Myanmar: "To gain access to nongovernment controlled areas", and "Access - they have it as local organizations where we do not many times." One respondent explained:

We partner with regional organizations to take advantage of the safe access they have to remote regions across Myanmar. Ultimately our aim is to provide significant employment directly to local communities, but given the security situation at this stage partnerships with local CBOs who have strong networks and access to conflict-affected regions is vital.

In addition, some respondents mentioned they collaborated with local organizations to build on existing local resources and skills, complementing their own organization's expertise:

These organizations have regional knowledge and expertise, which would be invaluable to helping us implement a project. We work with them for on-ground support and assistance, as well as providing a unique understanding of local contexts, complementing the technical expertise we are bringing.

Members of international organizations also wanted to benefit from cultural competencies of local staff, which was often mentioned in conjunction with the aforementioned local knowledge: "[B]ecause in some countries we are new and we need the local knowledge, expertise, cultural understanding."

When looking at organizational goals, the main reason for collaboration with local partners was to facilitate a sustainable delivery of aid (mentioned by $18 \%$ ): “For [the] purpose of sustainability, investing in partnership with local organizations with deeper understanding and connections with local people enables us to reach out to most impoverished and marginalize people." The same amount of organizations mentioned capacity building as a major motive to engage with local actors, as stated in the Grand Bargain: "Stated policy goal from the Grand Bargain: Profit from and contribute to the development of local capacities."

One respondent highlighted the need to adapt policies for sustainability and local capacity building in international organizations in his/her response:

There is no better way of sustainability than leaving the country, a state or a village with their own resources to serve their community. International organizations are outsiders, can stay in a country or a region for certain period and there is a time to leave. However, local organizations, local government and local people are the ones who will continue to serve for their people in longer term. For any international organization, it should be a must policy to transfer the expertise of international organizations to the local and invest time and resources to create spaces for local ownership and leadership.

Only a small number of respondents mentioned legal requirements, lower cost, and improved reputation as motives to partner with local organizations. For example, collaboration was sometimes mentioned as a requirement to achieve funding from other organizations or to be granted access to certain regions in Myanmar: "It's the only way the project is allowed to operate and the only real way to have any impact in government system strengthening." 


\subsection{Motives to Collaborate with International Organizations}

The biggest reason for representatives of local organizations to partner with international organizations was to gain access to funding and financial resources (mentioned by $47 \%$ of the respondents). A local manager reported: "The international funding requirement is [...] complicated, other requirement[s] such as procedures and reportings are also highly demand[ing]. Thus we have partnership with them." International partners were also seen as more likely to receiving grants, due to higher perceived levels of professionality: "To access larger, multi-year funds which require the prime grant holder to be more 'professional' than my organisation is."

Expert knowledge and skills were also identified as major motives for collaboration (mentioned by $45 \%$ of local respondents). Local organizations hoped for a sharing of skills and knowledge by engaging with international partners: "We partner with international organizations because they have experiences from different corners of the world and they can share their skills and knowledge they gained from the global experience." Local partners wanted to acquire skills from their international partners: "We also work with international organizations because we want to get new knowledge and skills from international organizations."

Fewer members of local organizations mentioned they collaborated for opportunities for networking and global outreach, to "[b]elong to the global landscape of stakeholders involved." Others saw chances for improving organizational capacity through learning and development in their collaboration. International organizations also engage in advocacy activities, as this is a very sensitive topic in Myanmar and viewed as negative by governmental authorities in the country. As international organizations are connected with the global aid community, they can carry out lobbying and advocacy activities at a higher level. Again, only few local nonprofit organizations relied on the knowledge, support, and independence of international partners to raise critical topics (Wallis and Jaquet 2011). Only four members of local organizations mentioned advocacy as a reason to collaborate with international organizations as they can execute "[a]dvocacy forces on government with partner[s] UN, INGOs, and embassies." When looking at the frequencies presented in Table 2, it shows that organizational goals seem to play a smaller role than program needs when it comes to collaborating with international partners, and program needs on both sides of the partnership seem to prevail.

\section{Discussion}

This study explores collaboration between local and international organizations providing development assistance in the Global South. While the existing literature often focuses on motives of local organizations, there is a lack of studies that assesses motives of international organizations, in particular when it comes to program needs (Ahmed et al. 2016; Hjortsø and Meilby 2013). The results of this study indicate that the use of local tuting program needs. Local organizations have a better understanding of local contexts and situations within rural areas that international organizations may want to explore. This contextual knowledge seems of particular importance in fragile states like Myanmar, where it can be hard for international organizations to collect reliable information on projects and beneficiaries. Further program needs constitute access to beneficiaries and relevant stakeholders through collaboration with local actors, such as local civil society organizations. International organizations engage with local partner organizations to gain geographic access, for example to remote areas and to areas of conflict. They also collaborate to build on existing local resources and skills and profit from cultural competencies of local staff. It was noted that international respondents expressed they 'used' resources of local organizations, rather than stating they wanted to 'acquire' some of these things for their own organization, signaling power imbalances.

In addition to these program needs, the most prominent reasons to collaborate with local organizations are the building of local capacity and the achievement of sustainability of aid, so that international organizations can at one point leave the project and country. These motives constitute organizational goals. Some international organizations work together with local partners to profit from a local organization's reputation and gain more visibility in the field. In addition, collaboration with local partners is seen as more cost effective in a few cases. A couple of international organizations mentioned that they had no choice but to collaborate with local organizations, as this is a requirement to achieve funding from other organizations or to be granted access to certain regions in Myanmar. As opposed to the results from the literature review (Bontenbal 2013), these results show that organizational goals such as lower costs and reputational gains do not seem to be the most prominent motives for collaboration for the majority of international organizations though.

When looking at the other side of heterogeneous partnerships and asking why local organizations collaborate with international actors, program needs relating to funding and financial resources prevail. As seen in the existing literature, international actors are often donor agencies that can provide grants and help secure project funding through other international actors (Burger and Owens 2013; Khieng and Dahles 2015). Collaboration 
with international organizations is seen as beneficial, as international actors are considered experienced and knowledgeable when it comes to complying with funding and reporting requirements. Fragile states such as Myanmar draw increased international attention following environmental jolts such as the Rohingya refugee crisis, which may lead to further INGO engagement in the country, as well as a change in INGO strategic programming from emergency aid to development assistance in the future (Blum 2001), bringing opportunities for further collaboration.

A high number of local organizations responded that they needed expert knowledge and skills to run their projects and programs. International actors bring technical skills and expertise to the country, for example in areas such as landmine clearance or election observations. As some of these subject matter experts cannot be found in the country, collaborations with international partners are formed. While international organizations talked about a 'use' of local resources, local partners seemed to have a stronger incentive to not only use resources, but to also acquire skills from the international partners that help them build up these resources and skills independently in the future.

The results of this study further reveal that local organizations tend to focus on the previously mentioned short-term program needs, rather than taking a long-term perspective that would help them to focus on organizational goals such as gaining enhanced legitimacy - also in the eyes of funders - or enhanced networks. This behaviour means that a discrepancy in powers between local and international organizations is likely to prevail. The local organizations' behaviour seems to be indirectly promoted by their international partners who focus on project outputs during the funding period of a project, and evaluations often do not go beyond this project horizon. Thus, development assistance steps short of promoting organizational development in more strategic areas, such as networking capabilities, governance, or fundraising. A continuing power imbalance between local and international organizations makes local organizations prone to charity hazard: Organizational activities are planned from project to project, depending on funding opportunities, as a long-term vision and the capability to act independently from international organizations decrease.

\section{Conclusion}

This study makes three major contributions to our understanding of heterogeneous partnerships. First, it investigates the relationship between local and international organizations, rather than focusing on differences between sectors. By looking at the case of Myanmar, insights from members of international and local organizations operating in a dynamic environment with frequent political changes and high economic and environmental risk are gathered. Second, this work derives a typology of different motives of aid, rather than exploring single types of motives. A frequency analysis helps to distinguish between prominent and not so prominent motives, yielding further insights into the often-criticized relationship between international and local organizations (Khieng and Dahles 2015; Pishchikova 2014). Third, this study focuses on international organizations and their specific needs in a partnership situation, as opposed to the resources they have to offer.

This study adds to the existing scholarship by regarding both international and local perspectives on motives for collaboration simultaneously. Results show that both groups of actors are primarily concerned with on-going program needs, rather than concentrating on mid- to long-term strategies and organizational goals, indicating a short-term perspective. This is understandable when one looks at the general structure of development assistance: International organizations design projects with a specific duration, usually ranging between three to five years. International staff is often deployed to a country for the duration of a project and will move on to different countries once the project has been completed (Loquercio, Hammersley, and Emmens 2006). This staff-, project- and funding-rotation means that organizations are incentivized to focus on the things that are right in front of them, rather than putting time and effort in longer-term strategies and goals.

Previous studies focused on the needs of local organizations, such as funding and the need for expert knowledge. Our expanded view, including the needs of international organizations, shows that international organizations do pursue a number of needs when collaborating with local partners indeed, such as an improved local understanding and access to beneficiaries. Slightly different approaches to these needs were identified: While international organization mainly reported they 'used' local knowledge and cultural competencies of their local partners, local organizations stated that they wanted to 'acquire' expert knowledge and skills. This finding adds to the existing literature and reveals that local organizations aim to build capacity by collaborating and learning from their international partners, indicating a more sustainable perspective. In contrast, the international organizations' position reflects a somewhat short-term perspective, where international organizations do not see a need to acquire local capacities for their own organization. These findings show that concerns relating to charity-hazard and power imbalances are valid, such as the criticism raised by Ahmad (2006), where heterogeneous partnerships were perceived as 'donor-recipient relationships', rather than true partnership. 
There are a number of practical implications that can be derived from this study and help to prevent power imbalances and charity hazard. International organizations must stop to view and evaluate their projects based on a project-cycle approach that does not go beyond the end of the project-funding period. In addition, development assistance needs to extend to more than single project funding. While many international organizations already engage in capacity building by enhancing local partner's project skills, trainings need to go beyond the project-horizon and extend to aspects relating to organizational goals, such as advocacy activities and networking. Of course, a big question that remains to be addressed is whether international organizations are willing to engage in activities that do not directly impact on their funded project or program. A focus on organizational goals would also mean that power imbalances would ultimately decrease, making the local organization a stronger partner confident enough to take on some tasks, such as advocacy, on its own (Almong-Bar 2018). While resource interdependence is positive in theory, it could be undesired from the international organization's point of view, as international organizations strive for power and control, allowing them to be the ones in charge of decision-making within the collaboration (Lister 2001; Saidel 1991).

Like any empirical work, this study has its limitations that give opportunities for additional research. This study's results are derived from the case of Myanmar. While Myanmar can be seen as an example for a country in the Global South with a very young public and nonprofit sector, there are cultural and economic differences to other countries with similarly young public and nonprofit sectors in the Global South. Responses that were received for this study may need to be interpreted with caution when deriving implications for other countries, keeping in mind cultural and economic differences. Future research can address this issue by replicating the study in similarly dynamic environments elsewhere, such as Haiti or the Philippines.

Additional knowledge about the functioning and structures of heterogeneous partnerships should ultimately contribute to a better integration of local organizations into supra- and international partnerships, decreasing power imbalances. This study does not assess the effects of the existence of different motives for collaboration on actual partnership performance. It follows the normative view that collaboration is a goal in itself, desired in the context of development assistance (Gazley and Brudney 2007; United Nations 2015, 2017). However, more research is needed to assess whether collaboration between international and local organizations can actually improve service delivery and sustainability in the Global South.

In addition to formal partners engaged in development assistance, recipients of services for development are further important stakeholders to address when looking at heterogeneous partnerships. Following calls for an enhanced sustainability of aid (Ahmed et al. 2016; Chahim and Prakash 2014), beneficiary involvement and its effect on resilience of local communities need to be considered more in detail. Future research should therefore analyse the effects of beneficiary involvement on the effectiveness of development assistance.

\section{References}

Ahmad, M. M. 2006. "The 'Partnership' Between International NCOs (Non-Covernmental Organisations) and Local NCOs in Bangladesh." Journal of International Development 18 (5): 629-38.

Ahmed, A., A.-R. Abdulai, I. K. Osumanu, and R. A. Salia. 2016. "The Contribution of Donor Support Programs to Decentralized Development: Learning from the District Level in Chana." International Journal of Public Administration 39 (11): 821-32.

Almong-Bar, M. 2018. "Insider Status and Outsider Tactics: Advocacy Tactics of Human Service Nonprofits in the Age of New Public Covernance." Nonprofit Policy Forum 8 (4): 411-28.

Ashman, D. 2001. “Strengthening North-South Partnerships for Sustainable Development." Nonprofit and Voluntary Sector Quarterly 30 (1): 74-98.

Asian Development Bank. 2015. Civil Society Briefs: Myanmar. Manila: Asian Development Bank.

Batliwala, S. 2002. “Grassroots Movements as Transnational Actors: Implications for Clobal Civil Society." Voluntas 13 (4): $393-409$.

Blum, L. 2001. "International NGOs and the Guatemalan Peace Accords." Voluntas 12 (4): 327-53.

Bontenbal, M. C. 2013. “Differences in Learning Practices and Values in North-South City Partnerships: Towards a Broader Understanding of Mutuality." Public Administration and Development 33 (2): 85-100.

Brinkerhoff, J. M. 2002. "Covernment-Nonprofit Partnership: A Defining Framework." Public Administration and Development 22 (1): 19-30.

Burger, R., and T. Owens. 2013. "Receive Grants or Perish? The Survival Prospects of Ugandan Non-Covernmental Organisations." Journal of Development Studies 49 (9): 1284-98.

Burger, R., T. Owens, and A. Prakash. 2018. "Clobal Non-Profit Chains and the Challenges of Development Aid Contracting." Nonprofit Policy Forum 9 (4). https://doi.org/10.1515/npf-2018-0026

Burgess, R. A. 2014. "'It Depends on Them' - Exploring Order and Disjuncture in Responding to Local Needs of AIDS Affected Communities in the Kingdom of Swaziland." Journal of Development Studies 50 (4): 467-80.

Casciaro, T., and M. J. Piskorski. 2005. "Power Imbalance, Mutual Dependence, and Constraint Absorption: A Closer Look at Resource Dependence Theory." Administrative Science Quarterly 50 (2): 167-99.

Chahim, D., and A. Prakash. 2014. "NCOization, Foreign Funding, and the Nicaragruan Civil Society." Voluntas 25 (2): 487-513.

Cheesman, N. 2010. “School, State and Sangha in Burma." Comparative Education 39 (1): 45-63. 
Chen, B., and E. A. Graddy. 2010. "The Effectiveness of Nonprofit Lead-Organization Networks for Social Service Delivery." Nonprofit Management and Leadership 20 (4): 405-22.

Chikoto, G. 2015. “Steering International NGOs Through Time: The Influence of Temporal Structuring in Covernment Accountability Requirements." Nonprofit Policy Forum 6 (1): 59-90.

Curtis, D. 2004. “'How We Think They Think': Thought Styles in the Management of International Aid." Public Administration and Development 24 (5): 415-523.

Elbers, W., L. Knippenberg, and L. Schulpen. 2014. “Trust or Control? Private Development Cooperation at the Crossroads." Public Administration and Development 34 (1): 1-13.

Gazley, B., and J. L. Brudney. 2007. “The Purpose (and Perils) of Covernment-Nonprofit Partnership.” Nonprofit and Voluntary Sector Quarterly 36 (3): $389-415$.

Gulati, R., and M. Sytch. 2007. “Dependence Asymmetry and Joint Dependence in Interorganizational Relationships: Effects of Embeddedness on a Manufacturer's Performance in Procurement Relationships." Administrative Science Quarterly 52 (1): 32-69.

Hjorts $\varnothing$, C. N., and H. Meilby. 2013. "Balancing Research and Organizational Capacity Building in Front-End Project Design: Experiences from Danida's ENRECA Programme." Public Administration and Development 33 (3): 205-20.

Holcombe, S. H., S. A. Nawaz, A. Kamwendo, and K. Ba. 2004. “Managing Development: NCO Perspectives?” International Public Management Journal 7 (2): 187-205.

Hudock, A. C. 1995. "Sustaining Southern NCOs in Resource-Dependent Environments." Journal of International Development 7 (4): $653-67$.

Inter-Agency Standing Committee. 2010. Response to the Humanitarian Crisis in Haiti-Following the 12 January 2010 Earthquake. 6-Month Report. Inter-Agency Standing Committee.

International Council of Voluntary Agencies. 2017. The Grand Bargain: Everything You Need to Know. Geneva: ICVA briefing paper.

Jensen, M. B., C. N. Hjorts $\varnothing$, J. Schipperijn, A.-R. Nik, and K. Nilsson. 2007. “Research Capacity Building through Twinning: Experiences from a Danish-Malaysian Twinning Project." Public Administration and Development 27 (5): 381-92.

Kendall, J., and M. Knapp. 1997. "The United Kingdom." In Defining the Nonprofit Sector, edited by L. M. Salamon, and H. K. Anheier, $249-79$. Manchester/New York: Manchester University Press.

Khieng, S., and H. Dahles. 2015. "Resource Dependence and Effects of Funding Diversification Strategies among NCOs in Cambodia." Volun$\operatorname{tas} 26$ (4): 1412-37.

Koehn, P. H. 2012. "Turbulence and Bifurcation in North-South Higher-Education Partnerships for Research and Sustainable Development." Public Organization Review 12 (4): 331-55.

Lindenberg, M. 2001. "Reaching Beyond the Family: New Nongovernmental Organization Alliances for Clobal Poverty Alleviation and Emergency Response." Nonprofit and Voluntary Sector Quarterly 30 (3): 603-15.

Lister, S. 2001. "The Consultation Practice of Northern NGOs: A Study of British Organizations in Guatemala." Journal of International Development 13 (7): 1071-82.

Loquercio, D., M. Hammersley, and B. Emmens. 2006. Understanding and Addressing Staff Turnover in Humanitarian Agencies. London, UK: Humanitarian Practice Network.

Matelski, M. 2016. "Civil Society, Foreign Aid, and Donor Dependency in Transitional Myanmar." In Border Twists and Burma Trajectories. Perceptions, Reforms, and Adaptations, edited by S. Kosem, 93-126. Chiang Mai, Thailand: Center for ASEAN Studies, Chiang Mai University.

Nolte, I. M., E. C. Martin, and S. Boenigk. 2012. “Cross-Sectoral Coordination of Disaster Relief." Public Management Review 14 (6): 707-30.

O'Brien, N., and S. Evans. 2017. "Civil Society Partnerships: Power Imbalance and Mutual Dependence in NGO Partnerships." Voluntas 28 (4): 1399-421.

OECD. 2017. Development Aid Rises Again in 2016 but Flows to Poorest Countries Dip. OECD. Accessed Apr. 26, 2019. http://www.oecd.org/dac/development-aid-rises-again-in-2016-but-flows-to-poorest-countries-dip.htm.

OECD. 2019. Aid at a Clance Charts - Interactive Summary Charts by Aid (ODA) Recipients. OECD. Accessed Apr. 26, 2019. http://www.oecd.org/dac/financing-sustainable-development/development-finance-data/aid-at-a-glance.htm.

Pfeffer, J., and C. R. Salancik. 1978. The External Control of Organizations: A Resource Dependence Perspective. New York: Harper and Row.

Pishchikova, K. 2014. “Greater Synergy and Improved Collaboration: Do Complex Partnerships Deliver on the Promise in Countries Emerging from Armed Conflict?" Voluntas 25 (1): 2-27.

Provan, K. G., P. Kenis, and S. E. Human. 2008. “Legitimacy Building in Organizational Networks.” In Big Ideas in Collaborative Public Management, edited by L. B. Bingham, and R. O'Leary, 121-37. Armonk, N.Y.: Sharpe.

Raschky, P. A., and H. Weck-Hannemann. 2007. “Charity Hazard - A Real Hazard to Natural Disaster Insurance?” Environmental Hazards 7 (4): $321-29$.

Raufflet, E., A. Berranger, and J.-F. Guin. 2008. “Innovation in Business-Community Partnerships: Evaluating the Impact of Local Enterprise and Clobal Investment Models on Poverty, Bio-Diversity and Development." Corporate Covernance 8 (4): 546-56.

Saidel, J. R. 1991. "Resource Interdependence: The Relationship Between State Agencies and Nonprofit Organizations." Public Administration Review 51 (6): 543-53.

Salamon, L. M. 1995. Partners in Public Service: Covernment-Nonprofit Relations in the Modern Welfare State. Baltimore, MD: Johns Hopkins University Press.

Spence, R., and F. Ninnes. 2007. "Building Relationships Across the Timor Sea: An Evaluation of the Australian/Timorese Friendship Agreements." Public Administration and Development 27 (4): 333-40.

Suchman, M. C. 1995. “Managing Legitimacy: Strategic and Institutional Approaches.” Academy of Management Review 20 (3): 571-610.

Transnational Institute and Burma Center Netherlands (TNI-BCN). 2011. Civil Society Caining Cround: Opportunities for Change and Development in Burma. Amsterdam: TNI-BCN.

United Nations. 2015. Millennium Development Goal 8: Taking Stock of the Clobal Partnership for Development. New York: MDC Gap Task Force Report 2015. New York: United Nations.

United Nations. 2017. The Sustainable Development Coals Report 2017. New York: United Nations. 
Vangen, S., J. P. Hayes, and C. Cornforth. 2015. “Coverning Cross-Sector, Inter-Organizational Collaborations.” Public Management Review 17 (9): 1237-60.

Wake, C., and B. Yu. 2018. The Rohingya Crisis: Making the Transition from Emergency to Longer-Term Development. Policy Brief 71. London: Overseas Development Institute.

Wallis, K., and C. Jaquet. 2011. "Local NCOs in Myanmar: Vibrant but Vulnerable." Humanitarian Exchange 51: 21-23.

Waugh, W. L. 2000. Living with Hazards, Dealing with Disasters: An Introduction to Emergency Management. Armonk, NY: M. E. Sharpe.

Young, D. R. 2000. “Alternative Models of Covernment-Nonprofit Sector Relations: Theoretical and International Perspectives." Nonprofit and Voluntary Sector Quarterly 29 (1): 149-72. 